\title{
Os recursos educativos e a utilização das TIC no Ensino Secundário na Matemática
}

\author{
María Carmen Ricoy \& Maria João V. S. Couto \\ Universidade de Vigo, Espanha
}

Resumo

A problemática subjacente ao estudo considera que a integração de recursos educativos de tipologia diversa, assim como a evidência da sua quantidade, revela uma forma de atuar da qual derivam, entre outros aspetos, as estratégias didáticas que envolvem o processo formativo. Por este motivo, neste estudo, pretende-se principalmente descobrir quais são, em geral, os recursos utilizados no Ensino Secundário e, em particular, na disciplina de Matemática, assim como conhecer os relativos às TIC. Trata-se de uma investigação por estudo de caso, tendo-se utilizado o questionário como instrumento para a recolha de dados, envolvendo 97 alunos do Norte de Portugal. Como conclusão, ressalta-se que os recursos educativos mais utilizados nas diferentes disciplinas continuam a ser os manuais e as fichas de trabalho, apesar de não motivarem os alunos. A mesma realidade está patente nas aulas de Matemática, usando-se apenas pontualmente algum outro recurso, como a calculadora gráfica, os computadores e a Internet.

Palavras-chave

Recursos educativos; TIC; Ensino Secundário; Matemática

\section{Fundamentação teórica}

Para elucidar sobre distintos posicionamentos em torno da temática objeto de estudo, abordaremos parte da sua fundamentação teórica no que se refere a alguns aspetos de tipo conceitual. Com a pretensão de clarificar 
componentes focais do núcleo investigado, centrar-nos-emos nos 'recursos educativos', 'recursos tecnológicos' e 'TIC'. Começamos por indicar que a expressão 'recursos educativos' representa uma enorme categoria, na qual outras mais específicas estariam incluídas. Referimo-nos a 'recursos tecnológicos' e 'TIC', que, na atualidade, podem ser subconjuntos diferenciados (sobre os quais aprofundaremos posteriormente).

\subsection{Delimitação da expressão 'recurso educativo'}

Desde o campo de conhecimento da Didática, o conceito de 'recurso educativo' conta com distintas aplicações e interpretações. Podemos encontrar uma diversidade de nomenclaturas que se utilizam como sinónimos e, na literatura científica especializada, pode-se ver um uso alternativo de diferentes términos. Rodríguez Rodríguez e Montero (2004) fazem eco da dificuldade em escolher o vocábulo a utilizar, dada a indefinição terminológica existente na expressão 'recurso educativo'. Exemplifica-se esta disparidade: "meios de ensino" (Cabero, 1999); "recursos educativos" (Salinas, Colom, \& Sureda, 1988; Fainholc, 2006); "meios didácticos" (Rodríguez Diéguez, 1995); "material curricular" (Gimeno, 1991); "recursos didácticos" (Lucena, 2008).

Ainda que alguns autores utilizem com maior preferência uns ou outros vocábulos, também há os que realizam um uso combinado. Por exemplo, Hernán e Carrillo (1988) empregam indiferentemente as expressões "material didáctico" e "recurso educativo", apesar de considerarem que esta última representa uma noção mais genérica e ampla, que abarcaria a primeira conceção da qual partilhamos. Em linhas gerais, podemos dizer que existem quatro tipologias de recursos associados ao processo formativo: humanos, metodológicos, ambientais (espaços físicos e infraestruturas) e educativos/didáticos. De facto, o professor Rodríguez Diéguez indicava que:

O conceito de recurso abarca desde um instrumento concreto até um plano de atuação articulado e orientado a uma situação determinada. Recurso é um retroprojetor. Mas recurso didático é também a previsão de uma série de atuações de um sujeito integrando distintos instrumentos com um objeto determinado: a informação mediante um vídeo, um manual e um programa interativo de ensino por computador (...). Uma ou outra aceção abarca o conceito de "recurso" (Rodríguez Diéguez, 1995, p. 25). 
Como vemos, no âmbito da Didática, as expressões 'recurso educativo' ou 'didático' são abordadas em sentido amplo e de forma alternativa, o que se reflete nas múltiplas terminologias escolhidas pelos autores. Tendo em conta as distintas concetualizações dos termos, é interessante começar por reduzir a ambiguidade existente. Para realizar uma aproximação concetual, e sem pretensão de esgotar o assunto em questão, seguidamente apresentamos algumas das definições e terminologia a utilizar: Martínez Sánchez (1996) diferencia entre "meios" (identificando-os com aqueles que estão elaborados com critérios didáticos) e "recursos" ou "materiais" (entendendo por isto os elementos ou objetos materiais suscetíveis de uso educativo, apesar de não serem criados com esta intencionalidade); Spiegel (2000) considera que um "recurso didáctico" pode ser tudo o que o docente reconheça de utilidade, como material, estratégia ou ferramenta de trabalho na aula; e Lucena (2008) considera que um "recurso educativo" é qualquer meio que o docente utiliza para a planificação ou o desenvolvimento das aulas: obter informação, ajudar na organização da aula, transmitir o conteúdo, facilitar a avaliação ou servir para apresentar exemplos.

Nós defendemos uma interpretação ampla e generalista sobre o conceito de 'recurso educativo', considerando que este posicionamento recolhe a tradição assim como a mais representativa evolução. Outro dos argumentos prende-se com a vantagem dele oferecer uma grande riqueza para a representação da própria ação, possibilitando o uso de um abundante elenco de expressões atribuíveis em diferentes situações. $O$ termo pode representar um objeto (material), um meio (associando-se à faceta comunicativa) ou uma estratégia didática (vinculada com o procedimento).

\subsection{Significado dos termos 'recurso tecnológico' e 'TIC'}

O conceito de tecnologia evoluiu muito ao longo da história e, mais ainda, na última década do século XX e na primeira do século XXI. A sua presença tornou-se evidente nos diversos campos de trabalho, inclusive o da educação, sendo que o significado desta tecnologia, atualmente, resulta bastante aberto e multifacetado (De Pablos, 1996).

A polissemia e a possibilidade de emergirem no tempo ou entrarem em desuso determinadas expressões podem dar lugar a diferentes polémicas 
sobre o seu significado. Para evitar esta tendência, Rodríguez Rodríguez e Montero (2004) mostram a necessidade de depurar o conceito de "material ou recurso educativo", substituindo-o, se for o caso, por outras subcategorias mais específicas como "recurso tecnológico e tecnologia da informação e da comunicação". Ballesta (1996) entende que as condições de uso associadas à natureza técnica dos materiais exigem um tratamento organizativo diferenciado e, neste sentido, entende ser conveniente distinguir os materiais que exigem o uso de suportes tecnológicos dos que não reúnem esta exigência (ainda que por detrás destes últimos estejam implícitos, muitas vezes, processos tecnológicos). Exemplos de materiais que exigem o uso de suportes tecnológicos podem ser o diapositivo, que necessita de um projetor para poder ser visualizado em todo o seu esplendor, e o mesmo ocorre com o vídeo ou um programa de computador. Como se depreende, as referidas expressões - "recurso tecnológico e tecnologia da informação e da comunicação" - estão envoltas num complexo enquadramento. Além disso, as TIC pertencem a um campo emergente, consequência do vertiginoso e constante desenvolvimento que experimentou a tecnologia.

A partir de uma conceção genérica, um 'recurso tecnológico' é um objeto que utiliza tecnologia, de qualquer tipo, no seu funcionamento. Continuando com este debate, e partindo, da mesma forma, de um posicionamento alargado, os recursos tecnológicos podem ser tangíveis, como o telefone, retroprojetor, computador e impressora, ou intangíveis, como um sistema operativo, uma base de dados e uma aplicação informática. Rodrigues e Colesanti (2008) consideram as TIC como uma configuração comunicativa que emprega como suporte as tecnologias disponíveis, podendo estas estar relacionadas com a informática ou não. Partindo do referido posicionamento genérico, torna-se evidente que as tecnologias se encontram presentes em todo o processo de desenvolvimento humano.

A denominação 'Tecnologias da Informação e Comunicação' é mais recente, tendo surgido nos finais dos anos 90 - em concreto, num documento elaborado pelo governo britânico. As TIC são constituídas por meios técnicos para manipular informação e promover a comunicação, incluindo o hardware e o software necessários, e surgem associadas às redes computacionais. Estão também vinculadas com a telecomunicação, como meio de difusão da comunicação, e com os elementos que promovem e possibilitam o 
processamento e sua transmissão em distintos formatos. Entre as definições que se foram gerando sobre a expressão 'TIC', recolhemos, a título de exemplo, as de dois autores. Blurton (1999) considera que as TIC são constituídas por uma diversidade de ferramentas e recursos tecnológicos (trata-se de tecnologias combinadas) que se utilizam para comunicar, criar, disseminar e obter informação. Spanhel (2008) sustenta que as TIC são meios tecnológicos ou electrónicos que se baseiam nos princípios da digitalização e da conexão em rede; acrescenta que fazer referência a estes dispositivos, no setor educativo, é falar de novas técnicas de informação e comunicação.

O significado dos termos 'recursos tecnológicos' e 'TIC' esteve e mantém-se associado aos aparelhos e à sua novidade. Com tudo isto, as referidas expressões têm sido utilizadas, entre os profissionais e científicos, de forma sinónima. Além disso, estas mudanças de cariz terminológico estão condicionadas pelo enorme potencial com que contam os meios tecnológicos de tipo digital ou TIC, em comparação com os analógicos. Entendemos, neste caso, que a transição é positiva, sempre e quando contribua para realmente melhorar e inovar o processo de ensino-aprendizagem.

\section{Estado da questão}

Beneficiando do exponencial crescimento das potencialidades das Tecnologias da Informação e Comunicação (TIC), alunos e professores dispõem de uma grande diversidade de recursos, cada vez com maior facilidade, a título institucional ou particular, que poderão contribuir para o sucesso dos processos de ensino-aprendizagem. Desta realidade é consciente a comunidade educativa, em especial professores e investigadores, na medida em que, assumindo posições cada vez mais exigentes e competitivas, reivindicam a utilização justificada das TIC, em prol da melhoria da qualidade da aprendizagens.

$\mathrm{Na}$ atividade docente, para além dos seus conhecimentos, o professor tem à disposição, na maior parte das situações, inúmeros artefactos que o poderão auxiliar, e não só em contextos de aula (Chamorro, 2003). Daí que, na planificação que realiza, além de definir os objetivos, conteúdos, atividades a concretizar, opção metodológica a adotar e tipo de avaliação, deva dedicar especial atenção à seleção dos recursos que melhor se ajustam ao contexto 
específico. São estes instrumentos, físicos ou virtuais, que tornarão os processos formativos mais apelativos, possivelmente mais rigorosos e de melhor compreensão, estimulando os alunos, potenciando a extensão das suas capacidades e, consequentemente, contribuindo para o sucesso das suas aprendizagens.

Da evolução tecnológica surgiram novos recursos que também estão ao serviço da educação, como por exemplo os computadores e o software associado (processadores de texto, folhas de cálculo, aplicações multimédia, entre outros), a Internet e as suas aplicações (entre estas, podemos referir a webquest, podcast, wikis, plataformas de teleformação), os quadros interativos, as calculadoras gráficas, os projetores multimédia, o smartphone e o tablet PC. Como Coomey e Stephenson (2001), consideramos que as TIC poderão ser utilizadas na promoção de modelos didáticos mais centrados no aluno, em rutura com as tradicionais conceções de ensino. Em especial, a educação online constitui uma oportunidade para transformar a tradicional pedagogia da transmissão na necessária pedagogia do diálogo (Dias \& Silva, 2005).

Em geral, estamos a falar de recursos com grande potencial e que se encontram, cada vez mais, acessíveis aos diferentes intervenientes dos processos de ensino-aprendizagem. Obviamente que cada um dos referidos recursos apresenta vantagens e inconvenientes no processo educativo. Da mesma forma, se evidenciam entraves e condições propícias para a sua utilização. Contudo, este tipo de análise deve ser elaborado inter-relacionando o oportuno contexto físico, on-line e formativo (Cabero, 2000). Neste sentido, diferentes autores acrescentam que, na inclusão das TIC em contextos educativos, há que combinar os aspetos tecnológicos e a vertente pedagógica pertinente (Wallace, 2002; Chen, Yu, \& Chang, 2007). Concordando com Pelgrum e Law (2003), a integração das TIC e a diversificação de tipos de recursos educativos no ensino cabe essencialmente aos docentes - daí que seja importante que eles os conheçam e explorem, na medida do possível, ou pelo menos que não repudiem a sua utilização. Além disso, caberá a cada professor optar pela combinação que melhor se ajuste ao seu estilo docente e à formação de que dispõe, assim como aos conteúdos a lecionar, atividades a desenvolver, características dos respetivos alunos (entre outras, a idade, motivações e hábitos de trabalho) e recursos educativos existentes na instituição. 
A mudança de práticas de ensino é lenta e pode oferecer resistências. De facto, diversos estudos demonstram que as TIC são ainda pouco utilizadas na escola (Gargallo, 2003; Loureiro, Pombo, Barbosa, \& Brito, 2010) ou estão "ao serviço do método expositivo" (Area, González, Cepeda, \& Sanabria, 2011, p. 196). Mas, se entendermos a evolução tecnológica, científica e social, compreenderemos a urgência e o imperativo da revolução educativa. Tendo em conta que vivemos numa 'aldeia global', onde a informação e o conhecimento científico circulam rápida e livremente na web, entende-se que as as atividades letivas se devem enriquecer. Pelos menos, espera-se que permitam desenvolver com maior plenitude a capacidade dos alunos para decidir ou escolher caminhos e selecionar percursos para uma aprendizagem mais autónoma - isto porque, como afirma Hargreaves (2003), a sociedade do conhecimento é uma comunidade de aprendizagem.

$\mathrm{Na}$ atualidade, o sistema educativo deve possibilitar aos alunos e professores o seu desenvolvimento na cultura digital, habilitando-os de capacidades para utilizar os meios informáticos, localizar a informação útil em cada caso, analisá-la, reconstruí-la, saber eleger entre o útil e o acessório, ser capaz de navegar e participar nas redes sociais, comunicar com outras pessoas e em outras línguas (Blas, 2005). Segundo Guattari (1992) e Cabero (2010), o educador deve estar preparado para o desafio de produzir novas alternativas com os recursos disponíveis. Contudo, estas exigências que se colocam aos docentes, também reconhecidas por Postholm (2006), ultrapassam $o$ ato de transmissão de conhecimentos, na medida em que deverão incutir no aluno a vontade de explorar, investigar, questionar, solucionar problemas, ser autónomo, curioso e com ânsia de saber.

\section{Problema e objetivos de investigação}

Como problemática subjacente ao presente estudo, estimamos que a inclusão de uma ou outra tipologia, assim como a quantidade dos recursos educativos utilizados, revelam uma forma de atuar da qual derivam, entre outros aspetos, as diferentes estratégias didáticas associadas ao processo de ensino-aprendizagem. Consequentemente, trata-se de uma problemática de investigação de grande importância. Por este motivo, para abordar estes tópicos, consideramos oportuno aprofundá-la, através do trabalho apresentado, particularmente na Matemática no Ensino Secundário. 
De facto, para que o implícito processo de inclusão dos meios educativos resulte eficaz, Feliz e Ricoy (2007) afirmam que necessitamos refletir e indagar sobre a ação. Nesta linha, pretendemos contribuir para 0 debate sobre formas alternativas de ensinar e aprender, no que se refere aos recursos utilizados para a realização das atividades. Nesta investigação, colocamos um dos focos principalmente nas TIC, a partir da disciplina de Matemática. Neste sentido, tratamos de analisar o uso que se faz dos recursos educativos e, em especial, das potencialidades das TIC, na aprendizagem da Matemática no Ensino Secundário. Consideramos que, ouvindo os alunos e estudando o conteúdo das suas opiniões, poderemos conhecer melhor a realidade.

Em concordância com o problema objeto de estudo já referido, delimitam-se os seguintes objetivos específicos de investigação: 1) descobrir quais são, em geral, os recursos educativos utilizados no ensino e, em particular, na disciplina de Matemática; 2) identificar os distintos tipos de recursos educativos e TIC que motivam os estudantes, em especial na disciplina de Matemática; 3) conhecer a perceção dos alunos sobre o uso que se faz das TIC na disciplina de Matemática.

\section{Método}

No presente trabalho, somente se apresenta parte de uma pesquisa mais ampla, que ainda se encontra em processo de desenvolvimento. Esta investigação foi levada a cabo mediante um enfoque qualitativo, de tipo descritivo e transversal. Trata-se de um estudo desenvolvido através de um inquérito por questionário. Delineou-se a partir do estudo de um caso específico, sendo que os seus resultados e conclusões poderão ser aplicados noutros contextos, mediante uma atitude crítico-reflexiva. Este trabalho segue a tendência na qual "as pesquisas desvinculam-se dos referenciais positivísticos e tendem para o estudo de questões delimitadas, locais, apreendendo os sujeitos no ambiente natural em que vivem" (Chizzotti, 2003, p. 229). Também podemos considerar que esta investigação se enquadra no que Stake (2000) define como "caso intrínseco", uma vez que procura uma melhor compreensão do caso de estudo. A referida abordagem centra-se na análise quantitativa microcontextual (completada com alguma informação de tipo qualitativo), que, como afirma o mesmo autor (Stake,1998), contribuirá, a 
partir da sua própria especificidade, para aprofundar o conhecimento da realidade.

Seguindo a Coller (2005), o estudo de caso é um método que permite, com certo êxito, descrever e compreender a situação objeto de análise, dentro de um contexto determinado. É também um facto que a conceção metodológica adotada é fundamental para o sucesso da condução do caso real analisado (Yin, 1989). A abordagem que nos ocupa tem como vantagem exigir, de início, menos recursos e poder ser assumida por um investigador ou uma pequena equipa (Duarte, 2008). Além disso, resulta de utilidade para a pesquisa, ao possibilitar o conhecimento da realidade baseado na objetividade (Latorre, Del Rincón, \& Arnal, 2003).

\subsection{Amostra}

A constituição da amostra não obedeceu a critérios probabilísticos de seleção dos participantes, pelas especificidades do tipo de estudo que se apresenta. De acordo com a metodologia adotada, responde a juízos pragmáticos, que não são incompatíveis com o rigor científico da investigação. Assim, os elementos da amostra foram selecionados intencionalmente, optando-se pela recolha de dados na escola onde lecionava uma das investigadoras. A boa acessibilidade aos participantes do estudo permitiu cumprir com a calendarização definida para a fase inicial.

Neste trabalho participaram 97 alunos de uma escola secundária de Portugal, do distrito de Braga. Trata-se de quatro turmas, nas quais os participantes frequentavam o $10^{\circ}$ e $11^{\circ}$ anos, com idades compreendidas entre os 14 e os 21 anos, sendo a média de idade 16,5 anos e a moda de 15 anos. Do total do grupo de participantes, 68 são do sexo feminino e 29 do sexo masculino. No conjunto dos participantes, quase metade já repetiu algum ano de escolaridade (42,3\%), daí que não resulte surpreendente a idade máxima registada. A maior parte dos alunos pertenciam a cursos profissionais $(57,7 \%)$, quase um quarto frequentava um curso científico-humanístico $(24,7 \%)$ e uma percentagem mais reduzida um curso tecnológico (17,6\%).

\subsection{Instrumento, procedimento e análise de dados}

Para o estudo, foi utilizada uma técnica de recolha de dados essencialmente quantitativa, que partiu da elaboração de um questionário ad 
hoc que servisse especificamente os objetivos da investigação apresentada, seguindo os procedimentos científicos oportunos. O referido instrumento foi constituído por itens de resposta fechada (Sim/Não) e por algumas perguntas abertas, das quais se procedeu à análise do conteúdo. Esta opção metodológica, que combina a recolha de informação quantitativa com a qualitativa, é frequente em investigações do âmbito educativo, isto porque, como afirmam Hill e Hill (2005), é particularmente relevante naquelas onde se pretende atingir uma melhor compreensão.

O questionário em causa contém diferentes dimensões de conteúdo, das quais destacamos as referidas a: acessibilidade, comunicação, atividades desenvolvidas, motivação, metodologia, recursos e avaliação. Por limitações de espaço, selecionamos, para este trabalho, as perguntas sobre os resultados relativos aos recursos educativos em geral e ao uso das TIC em particular. Para as questões de resposta fechada, procedeu-se a uma análise quantitativa. Os principais resultados obtidos através da folha de cálculo Excel (versão 2007) apresentam-se descritos em percentagem, e alguns deles ilustram-se através de gráficos.

No caso das perguntas de resposta aberta, elaborou-se um quadro ilustrativo, apresentando alguns exemplos com o número do questionário (ex.: Q3, que corresponde ao questionário $n^{\circ} 3$ ), o ano de escolaridade, diferentes excertos textuais analisados, assim como a interpretação dos benefícios, a partir da análise de conteúdo realizada. No corpo do artigo também é fornecida a percentagem de preponderância obtida, a partir da análise de conteúdo aplicada ao conjunto da informação das respostas.

\section{Resultados}

Os resultados desta investigação são apresentados, fundamentalmente, tendo em conta o uso dos recursos educativos, em geral, nas diferentes disciplinas e na Matemática, assim como das TIC nesta última. Nesta secção apresentamos os principais resultados, agrupados em três núcleos (nos quais também nos referimos à motivação que produzem): 1) uso dos recursos educativos, em geral, nas distintas disciplinas; 2) utilização dos recursos educativos na disciplina de Matemática; e 3) as TIC na Matemática. 


\subsection{Uso dos recursos educativos nas distintas disciplinas}

Quanto aos recursos educativos que, em geral, mais se utilizam nas aulas (ver gráfico 1), a maioria dos alunos afirma que são as fichas de trabalho $(72,2 \%)$, o manual escolar $(62,9 \%)$ e, com menor expressão, os jogos didáticos $(12,4 \%)$. Percentagens muito pequenas referem testes on-line (6,2\%), CD-ROM (5,2\%) e vídeos didáticos $(3,1 \%)$.

\section{Gráfico 1 - Recursos educativos utilizados em geral}

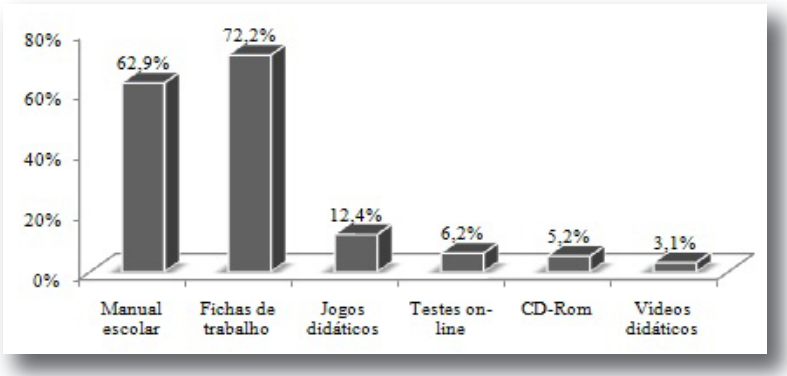

Questionados sobre os recursos que mais os motivam, os alunos divergem muito de opinião e nem sequer os que Ihes resultam atrativos reúnem uma percentagem elevada: jogos didáticos (21,6\%), vídeos educativos $(18,3 \%)$, testes on-line $(16,6 \%)$, fichas de trabalho $(15,4 \%)$, manual escolar (12,9\%) e CD-ROM (6,6\%).

\section{Gráfico 2 - Recursos utilizados e nível de motivação que suscitam}

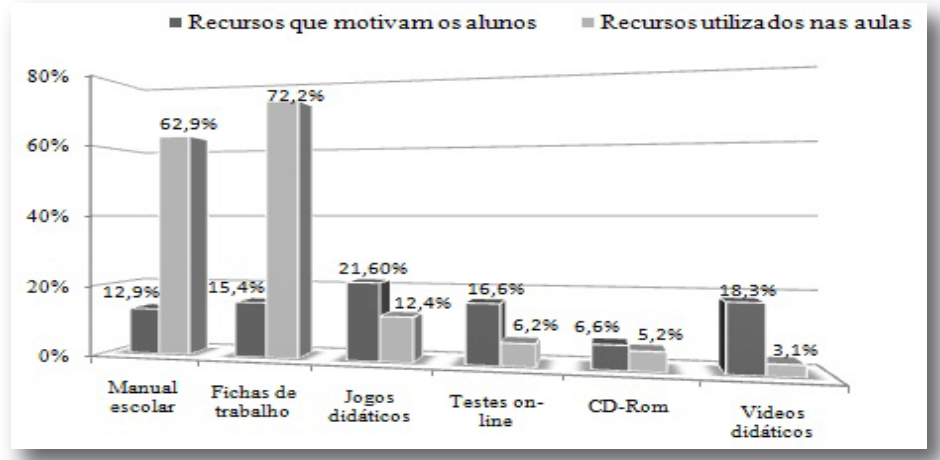


De notar que os recursos educativos mais utilizados, nas distintas disciplinas, não são os que agradam, em maior medida, aos alunos (ver gráfico 2). De facto, os livros de texto e as fichas de trabalho, pelos dados obtidos, motivam menos os alunos do que os jogos didáticos, os testes on-line ou os vídeos didáticos.

\subsection{Utilização dos recursos educativos na disciplina de Matemática}

No que se refere aos recursos mais utilizados nas aulas de Matemática, os alunos indicam: a calculadora gráfica $(79,1 \%)$, as fichas de trabalho $(75,3 \%)$, o manual escolar $(55,7 \%)$, os computadores e a Internet $(46,4 \%)$. Em menores percentagens, referem-se a algum tipo de software didático $(29,9 \%)$, e, em muito pequenas quantidades, ao quadro interativo $(7,2 \%)$, vídeos didáticos $(6,2 \%)$, outros recursos, sem indicar quais $(4,1 \%)$, objetos manipuláveis $(3,1 \%)$ e sensores (como, por exemplo, os de movimento e temperatura) para a recolha de dados $(1,0 \%)$.

Procedendo a uma comparação com as restantes disciplinas, constata-se que, da mesma forma, na disciplina de Matemática recorre-se sobretudo ao manual escolar e às fichas de trabalho do Ensino Secundário (ver gráfico 3).

\section{Gráfico 3 - Recursos utilizados em geral e, particularmente, na Matemática}

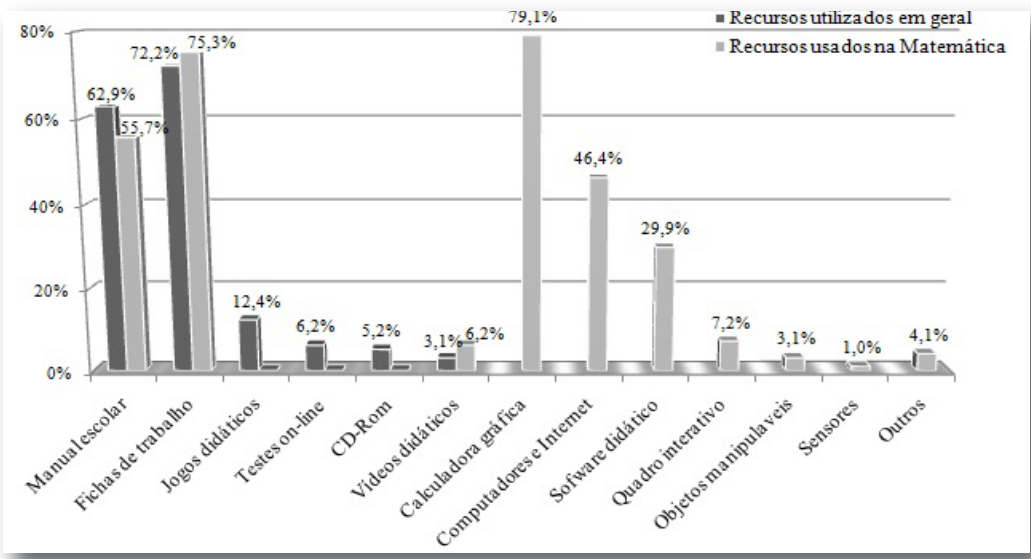


Em contextos informais, os recursos mais utilizados com o objetivo de trabalhar no âmbito da Matemática são: Internet (64,9\%), calculadora gráfica $(61,9 \%)$, jogos didáticos $(25,8 \%)$, objetos manipuláveis $(7,2 \%)$, software didáctico $(13,4 \%)$ e outros recursos $(3,1 \%)$. Alguns alunos referem a opção 'nenhum' (5,2\%).

Relativamente à disciplina de Matemática e ao número de professores que utilizam diferentes recursos para motivar os alunos, quase metade das opiniões $(44,3 \%)$ reflete que são poucos aqueles que adotam esta postura. Reforçando a ideia implícita, apenas uma pequena percentagem dos participantes $(1,0 \%)$ considera que os docentes promovem a utilização de distintos recursos didáticos, capazes de tornar mais apelativo o processo de ensino-aprendizagem. De salientar que foram poucos os alunos $(2,1 \%)$ que não refletiram o seu contributo sobre este assunto.

\subsection{As TIC na disciplina de Matemática}

Dos alunos que participaram no estudo, a percentagem dos que têm calculadora gráfica $(55,7 \%)$ é muito próxima da dos que não têm $(44,3 \%)$. A maioria afirma aprender mais, na disciplina de Matemática, quando usa a calculadora gráfica $(64,9 \%)$, e que é frequente recorrer às novas tecnologias nas aulas de Matemática (64,9\%).

A maior parte dos alunos é da opinião que tem ou já teve um professor, nas aulas de Matemática $(60,8 \%)$, ao qual associa a utilização do computador $(48,5 \%)$, da Internet $(46,4 \%)$ ou da calculadora gráfica $(42,3 \%)$, e, com menor expressão, indica os jogos didáticos $(30,9 \%)$. Como descobrimos, os alunos destacam os computadores e a Internet, pela sua importância para o processo de ensino-aprendizagem em Matemática. Surpreendentemente, manifestam nunca ter consultado uma página web sugerida por um manual escolar ou por um professor $(78,4 \%)$.

Quanto ao uso dos quadros interativos, uma percentagem importante dos alunos $(70,1 \%)$ ainda não assistiu a aulas de Matemática onde se tenha utilizado o referido recurso. Dos que já tiveram essa oportunidade, alguns referem vantagens tais como: o aumento no rigor e no grau de realismo das representações gráficas; o incremento da motivação; a melhoria dos resultados académicos e da qualidade das aprendizagens (quadro 1). 


\section{Quadro 1 - Algumas vantagens atribuídas às TIC nas aulas de} Matemática

\begin{tabular}{|c|c|c|c|}
\hline $\begin{array}{c}\mathrm{N}^{\circ} \text { de } \\
\text { questionário }\end{array}$ & $\begin{array}{c}\text { Ano de } \\
\text { escolaridade }\end{array}$ & Excertos dos alunos & $\begin{array}{l}\text { Interpretação dos possíveis } \\
\text { benefícios }\end{array}$ \\
\hline $\mathrm{Q}_{3}$ & $10^{\circ}$ ano & $\begin{array}{l}\text { "Ficamos a perceber melhor com o uso } \\
\text { dos quadros interativos." }\end{array}$ & $\begin{array}{l}\text { Possivelmente, a melhoria } \\
\text { qualitativa no processo de }\end{array}$ \\
\hline$Q_{77}$ & $11^{\circ}$ ano & $\begin{array}{l}\text { "Com os quadros interativos vê-se melhor } \\
\text { e aprende-se mais." }\end{array}$ & $\begin{array}{l}\text { aprendizagem se refletirá nos } \\
\text { resultados académicos dos } \\
\text { alunos. }\end{array}$ \\
\hline $\mathrm{Q}_{31}$ & $11^{\circ}$ ano & $\begin{array}{l}\text { "O uso de quadros interativos tem imenso } \\
\text { valor na geometria." }\end{array}$ & $\begin{array}{l}\text { Deduz-se, das opiniões dos } \\
\text { alunos, que o rigor e grau de } \\
\text { realismo das representacões }\end{array}$ \\
\hline$Q_{7}$ & $10^{\circ}$ ano & $\begin{array}{l}\text { "É mais fácil ver nos quadros interativos os } \\
\text { sólidos e figuras geométricas. Os } \\
\text { desenhos dos professores no quadro }\end{array}$ & $\begin{array}{l}\text { gráficas, decorrentes da } \\
\text { utilização do quadro interativo, } \\
\text { menoriza o esforço de abstração }\end{array}$ \\
\hline & & $\begin{array}{l}\text { negro com giz não se entendem muito } \\
\text { bem." }\end{array}$ & $\begin{array}{l}\text { muitas vezes implícito nos } \\
\text { conteúdos da disciplina de } \\
\text { Matemática. }\end{array}$ \\
\hline$Q_{9}$ & $10^{\circ}$ ano & $\begin{array}{l}\text { "É muito mais cativante aprender com o } \\
\text { quadro interativo e pode-se apresentar os } \\
\text { temas de estudo de uma maneira original." }\end{array}$ & $\begin{array}{l}\text { Previsivelmente, as vantagens } \\
\text { decorrentes da utilização dos }\end{array}$ \\
\hline$Q_{21}$ & $11^{\circ}$ ano & $\begin{array}{l}\text { "Com os quadros interativos os alunos } \\
\text { ficam mais entusiasmados." }\end{array}$ & $\begin{array}{l}\text { quadros interativos promoverão } \\
\text { a motivação no aluno por }\end{array}$ \\
\hline $\mathrm{Q}_{27}$ & $11^{\circ}$ ano & $\begin{array}{l}\text { "Com os quadros interativos cria-se um } \\
\text { ambiente de sala de aula completamente } \\
\text { diferente do habitual." }\end{array}$ & $\begin{array}{l}\text { melhorarem a qualidade das } \\
\text { suas aprendizagens. }\end{array}$ \\
\hline
\end{tabular}

Pouco mais de metade dos alunos afirma já ter utilizado software matemático $(61,9 \%)$. Contudo, quando têm que o especificar, não são tão expressivos, ainda que se refiram a: Graphmatica (49,5\%), GeoGebra $(30,9 \%)$, Geometer's Sketchpad $(2,1 \%)$ e outros $(3,1 \%)$. Muitos dos participantes $(64,9 \%)$ revelam estar disponíveis para seguir as sugestões dos professores, caso existam, relativamente à utilização de software matemático. Fora das aulas, a maior parte nunca pesquisou sobre software matemático $(67,0 \%)$ nem instalou qualquer programa no seu computador $(68,0 \%)$. Os alunos sustentam, na sua maioria $(52,6 \%)$, que os professores não aconselham software de utilização matemática.

\section{Conclusões e discussão}

Atendendo principalmente aos objetivos do trabalho aqui abordado e ao contexto analisado, a partir da amostra utilizada e dos resultados obtidos, apresentam-se as seguintes conclusões e discussão. 
Os recursos educativos mais utilizados na generalidade das disciplinas são o manual escolar e as fichas de trabalho, com todas as limitações que isto se sabe que supõe. De facto, outros estudos afirmam que o material didático mais usado continua a ser o de tipo escrito, em formato impresso (Ricoy, 2009), apesar de que, como descobrimos, não é o que desperta mais motivação entre os participantes. Outras investigações evidenciam o interesse dos alunos por determinados recursos educativos; em concreto, Marchesi e Martin (2003) destacam os computadores.

Como nas restantes disciplinas, desde a perceção dos alunos, os docentes de Matemática recorrem muito frequentemente ao manual escolar, às fichas de trabalho e também à calculadora gráfica. Esta última justifica-se pela adequação das suas possibilidades para a disciplina em causa. Além disso, quase metade dos alunos aponta os computadores e a Internet como recursos que, em algum momento, usam na Matemática. Outros recursos educativos, como o quadro interativo, os objetos manipuláveis e os sensores (nomeadamente os de movimento e temperatura) para recolha de dados, quase não são mencionados, apesar de existirem estudos que entendem as estratégias pedagógicas decorrentes da utilização de algum destes dispositivos como meio facilitador da aprendizagem dos alunos (Torres, Coutinho, \& Fernandes, 2008). Os quadros interativos, na opinião destes alunos, são pouco utilizados nas aulas de Matemática, muito embora estejam já disseminados pela grande maioria das escolas portuguesas. Pelo que se apresenta, os resultados deste estudo coincidem com outros onde também fica evidente que a organização do trabalho didático continua a ser dominada pelo manual escolar, que dá a tónica à atividade de ensino (Alves, 2006), apesar de Paiva (2003) defender que uma escola que não integre os novos meios informáticos corre o risco de se tornar obsoleta.

A maior parte dos participantes afirma já ter recorrido a software de utilidade para o estudo da Matemática e manifesta motivação por obter mais algum. Contudo, por iniciativa própria, fora das aulas, nunca pesquisaram nem instalaram qualquer aplicação informática para uso na referida disciplina. Uma possível explicação poderá estar no facto de os professores, de uma forma geral, não aconselharem a sua utilização, como percebe cerca de metade dos alunos. No que se refere ao uso de recursos educativos inovadores, na disciplina de Matemática, os estudantes partilham que poucos 
são os professores que realizam uma seleção adequada para promover a motivação. O que se apresenta neste trabalho revela-se também em consonância com outra investigação realizada, onde se constata um escasso uso dos recursos digitais apesar de se lhes reconhecer vantagens para a comunicação, representação gráfica, obtenção de informação e promoção do cálculo e da motivação (Ricoy \& Couto, 2011).

Nota-se um grande destaque, atribuído pelos participantes, aos computadores e à Internet como recursos relevantes para o processo de ensino-aprendizagem, apesar de a maior parte afirmar que nunca consultou uma página web a partir da sugestão no processo de formação. Assim sendo, é oportuno relembrar que as TIC encerram amplas possibilidades para a inovação educativa e para motivar os alunos, ainda que dependa da orientação didática atribuída por quem planifica e desenvolve o processo de ensino-aprendizagem (Pérez \& Pérez, 2008). Deste estudo, depreende-se que os novos recursos tecnológicos constituem um aliciante para a aprendizagem dos alunos, revelando-se como uma alternativa que é necessário revestir de valor pedagógico. Isto exige um longo caminho a percorrer, no que se refere à plena e efetiva integração das TIC, na medida em que diversos autores (Litwin, 2005; Pais, 2005) defendem que se trata de uma mais-valia para o processo formativo.

\section{Algumas sugestões}

É fundamental que os docentes atribuam sentido pertinente, no processo formativo, aos recursos educativos e às TIC, dando-lhes também utilidade inovadora, com criação de situações de aprendizagem motivadoras para os alunos. Será também importante que as entidades competentes promovam a formação adequada às novas exigências. Ramírez, Cañedo, Clemente, Jiménez, e Martín (2011) evidenciam uma necessidade formativa real dos docentes, neste âmbito. Relembrando que a resistência é a inimiga da inovação, no advento da web 2.0 os professores que não abracem o desafio de modernidade imposto estarão a limitar as oportunidades de aprendizagem aos alunos. À medida que o tempo avança, se alguma postura inflexível, de resistência às TIC, se mantiver, não facilitará o incremento do adequado clima de motivação nas aulas, podendo agravar o sentimento de desconforto para os alunos. Além disso, torna-se necessário evidenciar que 
novos cenários educativos ganham forma, como por exemplo o m-learning, do qual é testemunho o trabalho de Ramos, Herrera, e Ramírez (2010).

Muitos dos recursos educativos, potencialmente motivadores, que os docentes poderão utilizar com os seus alunos fazem já parte das infraestruturas das escolas ou do quotidiano dos adolescentes. Portanto, os professores podem tirar partido desta proximidade, dando maior utilidade didática, entre outros, a: quadros interativos, plataformas de aprendizagem, telemóvel, smarphones, jogos interativos, computadores, aplicações diversas de multimédia.

Aos alunos, exige-se-lhes curiosidade e gosto por aprender. Sugerimos aos docentes que o tempo que dedicam à utilização dos recursos educativos, particularmente das TIC, em contextos formativos, seja em prol de um ensino efetivo e de uma aprendizagem motivadora e significativa, trabalhando a partir do grande potencial que encerram. Em especial, lembramos que, nos contextos de aprendizagem on-line, há que promover posturas de responsabilidade que evitem distrações ou condutas reprováveis pelos alunos. Por último, incidir em que motivar os alunos supõe um desafio necessário a partir das mudanças requeridas por uma nova conceção pedagógica. Como tal, proporcionar aprendizagens dignas da sociedade do conhecimento, no século XXI, é uma obrigação fundamental dos docentes e dos responsáveis institucionais.

\section{Nota}

Esta contribuição enquadra-se num projeto de investigação (Ref. SFRH/BD/63472/2009) financiado pela Fundação para a Ciência e a Tecnologia (Portugal).

\section{Referências}

Alves, G. (2006). A produção da escola pública contemporânea. Campinas: Autores Associados.

Area, M., González, D., Cepeda, O., \& Sanabria, A. (2011). Un análisis de las actividades didácticas con TIC en aulas de educación secundaria. Pixel-Bit Revista de Medios y Educación, 38, 187-199. Disponível em http://redalyc.uaemex.mx/src/inicio/ArtPdfRed.jsp?iCve=36816200015 
Ballesta, J. (1996). Función didáctica de los materiales curriculares. Pixel-Bit - Revista de Medios y Educación, 5, 29-46. Disponível em http://www.sav.us.es/pixelbit/ pixelbit/articulos/n5/n5art/art53.htm

Blas, M. (2005). Las Tecnologías de la Información y la Comunicación (TIC) como apoyo a la innovación y al cambio. REICE: Revista Electrónica Iberoamericana sobre Calidad, Eficacia y Cambio en Educación, 3(1), 449-463. Disponível em http://redalyc.uaemex.mx/pdf/551/55130144.pdf

Blurton, C. (1999). New directions in education. In M. Tawfik (Org.), The world communication and information (pp. 46-61). Paris: UNESCO.

Cabero, J. (1999). Bases para el diseño, producción y utilización de los medios didácticos y materiales de enseñanza. In J. Cabero (Org.), Tecnología educativa (pp. 53-70). Madrid: Síntesis.

Cabero, J. (2000). Los usos de los medios audiovisuales, informáticos y las nuevas tecnologías en los centros andaluces. Los cuestionarios (I). In G. Underwood (Coord.), Y continuamos avanzando. Las tecnologías para la mejora educativa (pp. 467-502). Sevilla: Kronos.

Cabero, J. (2010). Los retos de la integración de las TICs en los procesos educativos. Límites y posibilidades. Revista Perspectiva Educacional, 49(1), 32-61. Disponível em http://tecnologiaedu.us.es/tecnoedu/images/stories/jca73.pdf

Chamorro, M. (2003). Didáctica de las Matemáticas para Primaria. Madrid: Pearson Educación.

Chen, H., Yu, C., \& Chang, C. (2007). E-Homebook system: A web-based interactive education interface. Computers \& Education, 49(2), 160-175.

Chizzotti, A. (2003). A pesquisa qualitativa em Ciências Humanas e Sociais: Evolução e desafios. Revista Portuguesa de Educação, 16(2), 221-236.

Coller, X. (2005). Estudio de casos. Madrid: Centro de Investigaciones Sociológicas.

Coomey, M., \& Stephenson, J. (2001). Online learning: It is all about dialogue, involvement, support and control according to research. In J. Stephenson (Coord.), Teaching \& learning online: New pedagogies for new technologies (pp. 37-52). Londres: Kogan Page.

De Pablos, J. (1996). Tecnología y educación. Barcelona: Cedecs.

Dias, S., \& Silva, M. (2005). Dialógica e interatividade em educação on-line. Revista da FAEEBA - Educação e Contemporaneidade, 14(23), 169-179. Disponível em http://www.uneb.br/revistadafaeeba/files/2011/05/numero23.pdf

Duarte, J. (2008). Estudos de caso em educação. Investigação em profundidade com recursos reduzidos e outro modo de generalização. Revista Lusófona de Educação, 11, 113-132.

Fainholc, B. (2006). Los medios en la enseñanza. Píxel-Bit - Revista de Medios y Educación, 27, 5-10. Disponível em http://redalyc.uaemex.mx/pdf/368/ 36802701.pdf

Feliz, T., \& Ricoy, M. (2007). From feedback about resources to the improvement of the curricular design of practical training as a generalization process. In L. Gürtler, M. Kiegelmann \& G. L. Huber (Eds.), Generalization in qualitative psychology (pp. 145-160). Tübingen: Ingeborg Huber Verlag. 
Gargallo, B. (2003). Un primer diagnóstico del uso de Internet en los centros escolares de la comunidad valenciana. Procesos de formación y efectos sobre la calidad de la educación. Valencia: Instituto Valenciano de Evaluación y Calidad Educativa.

Gimeno, J. (1991). Los materiales y la enseñanza. Cuadernos de Pedagogía, 194, 1015.

Guattari, F. (1992). Caosmose: Um novo paradigma estético. Rio de Janeiro: Editora 34.

Hargreaves, A. (2003). O ensino na sociedade do conhecimento. A educação na era da insegurança. Porto: Porto Editora.

Hernán, F., \& Carrillo, E. (1988). Recursos en el aula de Matemáticas. Madrid: Síntesis.

Hill, M., \& Hill, A. (2005). Investigação por questionário. Lisboa: Edições Sílabo.

Latorre, A., Del Rincón, D., \& Arnal, J. (2003). Bases metodológicas de la investigación educativa. Barcelona: Ediciones Experiencia.

Litwin, E. (2005). Tecnologías educativas en tiempos de Internet. Buenos Aires: Amorrortu.

Loureiro, M., Pombo, L., Barbosa, I., \& Brito, A. (2010). A utilização das TIC dentro e fora da escola: Resultados de um estudo envolvendo alunos do concelho de Aveiro. Educação, Formação \& Tecnologias, 3(1), 31-40. Disponível em http://www.educacaoadistancia.blog.br/ebook/A\%20utilizacao\%20das\% 20TIC.pdf.

Lucena, R. (2008). El profesor que programa: La programación como instrumento de trabajo. In J. C. Sánchez Huete (Coord.), Compendio de Didáctica General (pp. 207-241). Madrid: Editorial CCS.

Marchesi, A., \& Martín, E. (2003). Tecnología e aprendizaje. Madrid: Editorial SM.

Martínez Sánchez, F. (1996). Tecnología educativa y diseño curricular. In D. J. Gallego, C. Alonso \& I. Cantón (Coord.), Integración curricular de los recursos tecnológicos (pp. 13-30). Barcelona: Oikos-tau.

Pais, L. (2005). Educação escolar e as tecnologias da informática. Belo Horizonte: Autêntica.

Paiva, J. (2003). As tecnologias de informação e comunicação: Utilização pelos alunos. Lisboa: Ministério da Educação, DAPP.

Pelgrum, W., \& Law, N. (2003). ICT in education around the world: Trends, problems and prospects. Paris: UNESCO-IIEP.

Pérez, M., \& Pérez, E. (2008). Innovación curricular y nuevas tecnologías en la universidad ante el "espacio europeo de educación superior". In M. L. Sevillano (Coord.), Nuevas tecnologías en educación social (pp. 367-392). Madrid: McGraw-Hill.

Postholm, M. (2006). The teacher's role when pupils work on task using ICT in project work. Educational Research, 48(2), 155-175.

Ramírez, E., Cañedo, I., Clemente, M., Jiménez, J., \& Martín, J. (2011). Un estudio sobre Internet en las aulas. ¿Qué nos dicen los profesores de secundaria sobre el uso de estos recursos en sus prácticas? Revista lberoamericana de Educación, 56(1), 1-18. 
Ramos, A., Herrera, J., \& Ramírez, M. (2010). Desarrollo de habilidades cognitivas con aprendizaje móvil: Un estudio de casos. Comunicar, 17(34), 201-209.

Ricoy, M. C. (2009). Utilización de los recursos y factores que rodean el empleo de la prensa en la educación de jóvenes y adultos. Zer - Revista de Estudios de Comunicación, 14(26), 145-166.

Ricoy, M. C., \& Couto, M. J. (2011). As TIC no ensino secundário na Matemática: A percepção dos professores. Revista Latinoamericana de Investigación en Matemática Educativa, 14(1), 95-119.

Rodrigues, G., \& Colesanti, M. (2008). Educação ambiental e as novas tecnologias de informação e comunicação. Sociedade e Natureza, 20, 51-66. Disponível em http://www.seer.ufu.br/index.php/sociedadenatureza/article/view/9398/5743.

Rodríguez Diéguez, J. L. (1995). Nuevas tecnologías aplicadas a la educación y tecnología de la educación. In J. L. Rodríguez \& O. Sanz (Coords.), Tecnología educativa. Nuevas tecnologías aplicadas a la educación (pp. 21-43). Alcoy: Marfil.

Rodríguez Rodríguez, J., \& Montero, L. (2004). Indefinición terminológica y tecnología educativa. Pixel-Bit - Revista de Medios y Educación, 22, 51-65. Disponível em http://www.sav.us.es/pixelbit/pixelbit/articulos/n22/n22art/art2204.htm

Salinas, J., Colom, A., \& Sureda, J. (1988). Tecnología y medios educativos. Madrid: Cincel Kapelusz.

Spanhel, D. (2008). La importancia de las nuevas tecnologías en el sector educativo. In M. L. Sevillano (Coord.), Nuevas tecnologías en Educación Social (pp. 29-52). McGraw-Hill: Madrid.

Spiegel, A. (2000). La vida cotidiana como recurso didáctico. Hacia una escuela más autentica. Rosario: Homo Sapiens Ediciones.

Stake, R. (1998). Investigación con estudio de casos. Madrid: Morata.

Stake, R. (2000). Case studies. In N. K. Denzin \& Y. S. Lincoln (Eds.), Handbook of qualitative research (pp. 435-454). London: Sage.

Torres, T., Coutinho, C., \& Fernandes, J. (2008). Aplicações e modelação matemática com recurso à calculadora gráfica e sensores. Revista Iberoamericana de Educación Matemática, 15, 9-31.

Wallace, R. (2002). The Internet as a site for changing practice: The case of Ms. Owens. Research in Science Education, 32(4), 465-487.

Yin, R. (1989). Case study research - Design and methods. USA: Sage. 


\title{
EDUCATIONAL RESOURCES AND THE USE OF ICT IN SECONDARY EDUCATION IN MATHEMATICS
}

\begin{abstract}
The problem underlying the study considers that the integration of resources from diverse typologies, as well as the evidence of its quantity, reveals a way of acting from which teaching strategies that involve the training process were derived. For this reason, this study is mainly intended to find out what are, in general, the resources used in Secondary Education and, particularly, in Mathematics, as well as meet those relating to the use of ICT. This is a case study, which used a questionnaire to collect data, and involved 97 students from northern Portugal. As a conclusion, we note that the educational resources that are more used in different disciplines still are the textbooks and worksheets, although they didn't motivate the students. The same reality is visible in the Mathematics classes, where only occasionally other resources such as graphic calculators, computers and Internet are used.
\end{abstract}

Keywords

Educational resources; ICT; Secondary Education; Mathematics

\section{LOS RECURSOS EDUCATIVOS Y LA UTILIZACIÓN DE LAS TIC EN LA ENSEÑANZA SECUNDARIA DE LAS MATEMÁTICAS}

Resumen

La problemática subyacente al estudio considera que la integración de recursos educativos de tipología diversa, así como la evidencia de su cantidad, revela una forma de actuar de la cual derivan las estrategias didácticas que se utilizan en el proceso formativo. Por este motivo, en este estudio, se pretende principalmente descubrir cuáles son los recursos utilizados en la Enseñanza Secundaria y, en particular, en la disciplina de Matemáticas, así como conocer los relativos a las TIC. Se trata de una 
investigación por estudio de caso, utilizándose el cuestionario como instrumento para la recogida de datos, implicando a un total de 97 estudiantes del Norte de Portugal. Como conclusione, resaltar que los recursos educativos más utilizados en las diferentes asignaturas continúan siendo los libros de texto y las fichas de trabajo, a pesar de que no motivan al alumnado. La misma realidad está patente en las aulas de Matemáticas, utilizándose sólo puntualmente algún otro recurso, como la calculadora gráfica, los ordenadores e la Internet.

Palabras-clave

Recursos educativos; TIC; Enseñanza Secundaria; Matemáticas

Recebido em Julho/2011 Aceite para publicação em Julho/2012

Toda a correspondência relativa a este artigo deve ser enviada para: María Carmen Ricoy, Universidade de Vigo, Facultade de Ciencias da Educación, Avd./ Castelao, s/n 32004 Ourense, España. E-mail: cricoy@uvigo.es 